The Construction of the Older Worker: Privilege, Paradox and Policy

\author{
Susan Ainsworth \\ School of Business and Government \\ The University of Canberra ACT 2601 \\ Australia \\ susan.ainsworth@canberra.edu.au \\ Cynthia Hardy \\ Department of Management \\ University of Melbourne \\ Parkville 3010 \\ Australia \\ chardy@unimelb.edu.au
}




\title{
The Construction of the Older Worker: Privilege, Paradox and Policy
}

\begin{abstract}
Our study of a public inquiry shows how particular constructions of the older worker - as male and lacking in self esteem - were privileged as a result of discursive manoeuvres that established comparative disadvantage among different identities. Paradoxically, traditional gender stereotypes were subverted to construct female willingness to accept low status, low paid jobs as a reason why they did not need help in the form of policy initiatives; while men's intransigence meant they deserved greater support. A second paradox concerned the construction of the older worker as lacking self-esteem: it led to self-esteem based solutions that were the responsibility of the individual to remedy but, precisely because older male workers lacked self-esteem, they were unable to help themselves and needed the help of employment and welfare agencies. Thus we can see the link between particular identity constructions, discourse and the reproduction of particular institutional structures.
\end{abstract}

Key Words: critical discourse analysis, identity, older worker, unemployed. 


\section{Introduction}

Older workers constitute a growing proportion of workforces and populations in many countries around the world (Glover and Branine 2001; McMahan and Phillips 2000; Pearson 2003; Encel 2003). As a result, governments and organizations are concerned with the implications of an older workforce and its impact on economic growth, productivity, and the labour market. A common response has been to develop policies and programs to encourage older people to remain in the workforce for as long as possible and to find ways to help them re-enter it in the event of job loss (Encel 2003; OECD 2005). Yet despite such measures, many countries encounter declining labour force participation rates by older workers; early exit from the workforce due to redundancy and early retirement; difficulties in finding employment once they become unemployed; and age discrimination against older workers who are in employment (Duncan 2001; Loretto and White 2006; McGoldrick and Arrowsmith 2001; Redman and Snape 2002; Taylor and Walker 1998).

A range of academic disciplines have been used to study the problems faced by older workers, and to learn why they persist even in the face of policies and practices designed to eradicate them; but only discourse analysis interrogates the concept itself i.e., who and what is the "older worker" and how this identity is constructed (Ainsworth and Hardy, 2004). Accordingly, this study uses discourse analysis to examine the construction of this identity and the policy implications that follow from it. Building on earlier discursive work on prejudice in relation to gender and race/ethnicity (Edley and Wetherell 1997; Garnsey and Rees 1996; Gill 1993; Kleiner 1998; van Dijk 1997; Wodak 1996); and on the contradictions that arising from the mixing of different discourses in contemporary texts (Fairclough 1995), we show how age discrimination intersects with other discourses to produce a particular kind of older worker. By examining the discursive processes that construct identity, particularly struggles around comparative disadvantage, we are able to show how certain versions of older 
worker identity are privileged; identify a number of paradoxes that are embedded in the process; and discuss the policy implications that have material outcomes not only for individuals categorized as older workers, but also those who fail to make this category.

The study is based on an examination of the texts of a public parliamentary inquiry into the older worker and the problems they faced in Australia. It included 2000 pages of texts that included the report, transcripts of hearing, press releases and written submissions that were generated over an 18-month period and which allowed us to trace discursive processes over time. To examine this large body of texts, a number of systematic analyses were conducted to form a meta-analysis consistent with Critical Discourse Analysis (CDA) which aims to focus on "the role of discourse in the production and reproduction of power abuse or domination” (van Dijk 2001: 96). In so doing, the study adopts a social constructionist perspective. Rather than treating identity as innate or stemming from essential characteristics, we see identity as accomplished in social interaction (Hacking 2000).

The remainder of the paper is structured as follows. We first review the discursive literature on identity and age, with particular reference to the work conducted under the auspices of critical discourse theory. Second, we provide an overview of the case study and methods of data collection and analysis that we used. Third, we present our findings, which show the construction of the older worker as male and lacking in self-esteem. Our analysis shows, however, that this construction of the older worker was exactly that - one particular construction in which various discursive manoeuvers to establish comparative disadvantage served to suppress female versions of older worker identities, as well as constructing the male older worker as psychologically deficient. Finally, we conclude with discussion of the insights into how age, gender and employment intersect with each other in particular ways to produce particular outcomes for identity which, in turn, have implications for subsequent policy recommendations. 


\section{Identity, Age and Discourse}

There is a tradition within CDA of studying the construction of social identities, showing how social categorizations or identities are brought into being and how these categorizations have important practical effects for those targeted by those categories and those involved in their construction (e.g. Phillips and Hardy 1997; Ainsworth \& Hardy, 2004). Such research has been particularly important in showing how social categories or identities that may appear natural or obvious are instead contingent, unstable and the product of particular historical circumstances (Hall 1996). Identity’s relational nature contributes to its contingency and instability - it is achieved by differentiating and excluding that which is “Other”, however this exclusion is conditional and apparent (Laclau 1990).

These ideas underpin a body of discursive research that has examined discourses of difference (Wodak 1996) to explore how the identity of marginalized groups is discursively constructed in relation to particular local contexts. Most often this research has focused on the construction of gender and ethnic/racial identities and prejudice (e.g. Cameron 1997; Edley and Wetherell 1997; Kleiner 1998; Tannen 1994; van Dijk 1984; Wodak 1997). Some researcher have focused on particular age identities such as youth in the discursive practices of teenagers (Tannock 1999) and young adults’ reactions to media discourse and representations of Generation X (Williams, Coupland, Folwell and Sparks 1997). Research has also focused on the discursive construction of older age identities in the context of consumption and delivery of services, including health and aged care (Coupland, Coupland and Giles 1991; Stephenson, Wolfe, Coughlan and Koehn 1999; Ylanne-McEwen 2000); and on intergenerational relations and constructions of age across the life-course (Coupland, Coupland and Giles 1991; Coupland and Nussbaum 1993). Tretheway (2001) combines age and work in her study of midlife professional women, and the reproduction of and resistance to the master narrative of ageing-as-decline (Gullette 1997: 160-161). 
We seek to contribute to this literature by examining the construction of age and work identities and their intersection with other current discourses. Given the prominence of political and public policy concerns about the consequences of population and workforce ageing, we explore these issues within the specific context of a public parliamentary inquiry to examine two key questions: how is the identity of the older worker constructed; what are the policy implications of such constructions?

\section{Methods}

Our exploration of the construction of older worker identity and its policy implications is located in a specific context - an Australian public parliamentary inquiry into the problems faced by older workers following unemployment. The inquiry was held in a particular political and social context: it was launched in 1999, the United Nations International Year of Older Persons and was underpinned by government concerns over the public costs of supporting ageing populations, including the older unemployed. The commencement of the inquiry was accompanied by advertisements and media releases calling for submissions from all interested organizations and individuals. On the basis of these submissions, the inquiry Committee held a series of public hearings throughout Australia. From this written and oral evidence, the Committee released a final report in August 2000 (Age Counts: An Inquiry into Issues Specific to Mature-Age Workers) which included specific policy and program recommendations to address the problems facing older workers who become unemployed. The inquiry attracted a wide range of participants including employer groups, unions, government departments and private individuals, and most of the texts it generated were publicly available, collected and analyzed.

In the first stage of our data analysis, we made a comparison between early and later inquiry texts, looking for general patterns in the construction of older worker identity that might indicate themes or topics that could then be pursued through the entire corpus of texts. 
This initial analysis generated a number of key findings including (a) the disappearance of female versions of older worker identity present in the early texts from the later texts, leaving a predominantly masculinized view of older workers and (b) that older unemployment was constructed using psychological rather than economic discourse. These initial findings formed the basis for more detailed analysis where we searched for patterns of similarity and difference in versions of identity, traced how they were constructed in relation to other social identities, and examined the discursive resources used to establish particular constructions. We then explored their functions and effects of particular discursive patterns within the immediate context of the text (e.g., the particular hearing or report), drawing on previous discourse research into gender, racial identity and inequality (e.g., Gill 1993a, 1993b; Wetherell and Potter 1992), as well as examining how they related to the policy recommendations which resulted from the inquiry.

In relation to the first finding - the disappearance of female versions of the older worker identity - we coded all texts for references to age and then age and gender in combination. We then conducted more detailed analyses of sections of text containing these references focusing on argumentation strategies of group construction and differentiation (Wodak 1996), topic choice (in the social interaction of the public hearings) (Pomerantz and Fehr 1997), constructions of agency and social processes focusing on transivity, mood and theme (Halliday and Matthiessen 2004; Paltridge 2000) and patterns of cohesion (including word choice, Fowler 1991, 1996) to identify how such disappearance was discursively accomplished.

In relation to the second finding, we explored how older (male) unemployment was discussed in psychological, rather than economic terms. We coded all texts for references to psychological or psychotherapeutic terms and analyzed the context of their use. More specifically we examined which terms were used most frequently and how they were being 
used (their functions) in accounts of older unemployment. We also noted patterns of lexical cohesion, transivity, mood and theme, and the tenor of texts relating to the relationship between speakers and listeners or readers and writers (Paltridge 2000).

\section{Findings}

In this section, we explore how, through a series of discursive struggles around comparative disadvantage compared to various other identities, the older worker was constructed as male and as suffering low self-esteem as a result of unemployment.

\section{The Older Worker as Male}

From the early inquiry texts, we identified four dominant, gendered versions of older worker identity: two male and two female. All were unemployed workers insofar as the inquiry was explicitly concerned with examining issues relating to older people who were unemployed and were seeking to regain paid employment or to start a small business. The white collar male was an educated former middle manager or professional made redundant from long term career and “overqualified” for available jobs. The blue collar worker was a skilled or semi-skilled worker with non-transferable skills in a declining industry, previously the male breadwinner, but who was now unemployed having been retrenched from a long term occupation and living in an economically depressed region. The flexible female was employed in flexible jobs - low-paid, casual, and part-time - in the expanding service sector, with a discontinuous work history mainly due to family responsibilities. She had low levels of formal education, and was classed as unskilled and in a precarious financial position. The hidden unemployed older worker was also female and seeking work and/or attempting career re-entry or occupational change following a discontinuous work history due to family responsibilities and periods of unemployment. Typically, she was the recipient of a sole parent pension or was the spouse of a working male.

Of these four identities only the male identities survived to appear in the later texts 
produced in the parliamentary inquiry as needing support. When the Committee's final report was tabled in federal parliament, it was older men who were singled out as particularly disadvantaged: "Being a mature age worker in Australia today, particularly a male, means that you are one of the most disadvantaged groups for labour market assistance” (House of Representatives, Parliamentary Votes and Proceedings, 1998-1999-2000: 17247). Subsequent analysis showed that the flexible female was suppressed because she was constructed as relatively successful in gaining employment, compared to older male workers, and thus not in need of government assistance (Ainsworth, 2002). The hidden unemployed, on the other hand, remained hidden: the discursive struggle to broaden the category of unemployed to include those not registered as unemployed or who were on other forms of government support such as sole parent pensions, was unsuccessful, largely because these identities were constructed as “non-workers”. In different ways, both feminine versions of older worker identity were constructed as relatively advantaged, compared to older men, despite efforts to contest this interpretation. In this section, we explain the disappearance of the two female identities.

\section{Comparative (Dis)advantage}

Versions of older worker identity were constructed in relation and comparison to other social identities and we found that these relational processes were central to establishing the comparative disadvantage of older male workers. Masculine versions of the older worker were routinely juxtaposed against other identities in ways that leveraged these groups' already established disadvantaged status. We found that older workers were defined in relation to the following recognizable disadvantaged groups: women, unemployed youth, indigenous groups, people from non-English speaking backgrounds, and people with disabilities, with the first two groups being most common. These groups were constructed as presenting a competitive challenge, vying for attention and resources from government, welfare groups and employers and more directly, competing for jobs, as in the following example. 
Single breadwinners who are older unemployed persons should be entitled to the same rights and privileges as women, Aboriginal and Torres Strait Islanders and the handicapped. This is based on the discrimination that is taking place in the workplace against the older unemployed on re-entering the workforce. (Submission 87)

The most common comparison was between the older male and older female worker and, when these comparisons were made, the clear pattern was that the former was clearly disadvantaged in comparison to the latter. Constructions of relative feminine advantage were then accomplished in a number of ways.

First, repeated reference to statistical data based on gender comparisons were made in both written submissions to the inquiry and in the public hearings. Statistical data on older people’s labour force participation rates was frequently categorized by gender, followed by discussion of whether older male or older female workers were more disadvantaged. In this context, the use of trend data typically led to the conclusion that older male workers were relatively worse off because women's labour force participation rates were increasing over time, with an implicit projection of continued improvement. Once this view took hold in the social interactions of the public hearings, our analysis shows that evidence disconfirming the statistical results was routinely discounted instead of being pursued. In the example, below, having been convinced that the data showed older women's greater labour market advantage, committee members then re-cycled this view in the form of questions to witnesses. If witnesses did not support or confirm this view, discussion was regularly cut short by abrupt topic changes as in this case, where the committee member switches from a question on whether it is easier to place women to a question regarding the Russian community:

Mr SAWFORD [Committee] - Right across the board. What about gender in terms of male and female? Is it easier to place women than men?

Witness - No.

Mr SAWFORD [Committee] - Were there any Russian community employers who you have contacted who have perhaps come in previous generations? (Public Hearing, Tuesday 16 November 1999, p. 705) 
A second way in which older male workers were constructed as disadvantaged compared to females, was their portrayal as the victims of reverse prejudice and antidiscrimination legislation. Ideas about the lesser social and economic power of women in the labour market were inverted to construct a position of their relative privilege. The traditional association between men and careers, work continuity and greater economic success were recast as constraints that inhibited men's capacity to change and made unemployment harder for men to bear because paid work was seen as more important to their identity. In the following example, the case for greater government attention and assistance for older male workers is made by conveying a sense of urgency about their situation. This is achieved by a pattern of lexical cohesion ('first three months', 'when', 'after', 'six or 12 months', 'at the moment') as well as foregrounding circumstances of time at the beginning of the first few clauses (in theme position). Having established a sense of urgency, older male workers are constructed as a greater priority by a progressive narrowing of relational identity categories: the witness moves from discussing the need for immediate assistance to the unemployed in general, to the older unemployed, to older unemployed men:

Witness - The first three months after losing a job or being made redundant are critical because that is when you need the help, not after you have been out of work for six months or 12 months. This is particularly so for an older worker, and again I will say particularly a male, because I think men are very much shaped by how they see themselves as a contributing member of paid work force, and women perhaps less so, at the moment. (Public hearing, Thursday, 16 September 1999, p. 426)

Women, on the other hand, were constructed as advantaged in comparison to male versions of the older worker. The flexible female was advantaged because she was willing to accept low paying, demeaning work that men would reject. Paradoxically, men’s intransigence and unwillingness to accept low status jobs meant they needed help, while cooperation and reasonableness on the part of women was used against them. The following quotation illustrates some of the discursive processes that contributed to this construction. The first concerns the nature of the inquiry's shared sense-making. The social interaction of the 
public hearings encouraged agreement between participants - in this example, the committee member poses an initial question to a witness (are women more flexible then men?), but then goes on to pose a series of further questions that assume a positive answer to the first. In this way, the relative flexibility of older women becomes established as a "fact" and witnesses are encouraged to confirm and validate the opinions of committee members and participate by elaborating on those opinions:

Ms GAMBARO [Committee] - I now want to talk to you about flexible attitudes to work, and part-time work versus casual work. Do you have any information that shows whether or not women are much more flexible than men when it comes to the prospects of working on a part-time or casual basis? Are women like that because they have gone through a life cycle curve where they have had a full-time job, had a family, then had to go back into the work force and so are more psychologically suited to parttime or casual work? Could you shed some light on that?

Witness - I have certainly found that women are more flexible. They tend to adapt more quickly than men do, particularly men who have been in jobs where it has been a traditional male situation, where they have all worked in the same industry over the years. They expect to stay there and expect their kids to go into that industry. I do not know the entire reason but the things you have suggested are certainly part of the reason. Perhaps it is because women are naturally more intuitive and mentally able to move around a bit more.

Ms GAMBARO - I am not a psychologist but is it because women are able to be more flexible in the choice of work they do, as you have said? Or is it a lifestyle thing? Is it because women are used to doing part-time work?

Witness - I do not think they have been stuck in as many stereotypes. That sounds odd because being in the kitchen is a bit of a stereotype, but when women have wanted to go out to work, as they have done increasingly in recent times, they are not told, "You're not to go into this job." Apart from hairdressing, nursing and childcare, maybe, the options are more open. There is less expectation that they will go into one of these set types of careers. The whole notion of a career for life is not always locked in as much with women. (Public hearing, Wednesday $15^{\text {th }}$ September, 1999, p. 246)

A second discursive feature of this exchange concerns constructions of agency of

older women. Relational processes dominate when older women are discussed so that the focus is on describing their characteristics (attributes) rather than positioning them, for example, as the active participants in initiating change. Where change does occur, older women are still not represented as actors effecting change, but as having undergone a change 
(i.e., having experienced a life cycle curve rather than initiating a career change). Thirdly, patterns of cohesion contributed to the construction of older women and older men as comparative and companion identities. The initial comparison between older men and older women posed by the committee member is referenced by later comparative adjectives and adverbs. Further distinct patterns of lexical cohesion are formed that differentiate between older men and older women. For example, older women are presented as advantaged by their 'mobility' reinforced through the repetition of words and phrases such as 'flexible', 'much more flexible’, ‘adapt more quickly', ‘move around a bit more'; whereas older men are disadvantaged by their greater stability and continuity which contributes to their being 'stuck' and 'locked in', subject to 'set types of careers' and unable to take advantage of new flexible work options.

The flexible female's more marginal workforce attachment, lower expectations of work and their concentration in low-paid, low-skill contingent jobs in the service sector thus became subverted and used as signifiers of relative privilege and success. In competition for the same low quality jobs, women were constructed as relatively successful: they could get jobs that men could not, because of employers' gender discrimination. This discursive reframing is illustrated in the following quotation where a complex sentence structure shifts the focus from older women’s lower labour market expectations to employers’ perceptions. Multiple clauses accomplish this repositioning where older women are constructed as able to take advantage of employers’ discrimination against older (male) workers:

Mr BARRESI [Committee member] - I want to return to the issue of women finding work. Rather than there being a greater predisposition for women to take on a lower paid job, can I put it to you that perhaps another way of looking at their greater participation is that the employer perception itself is to the advantage of the woman, particularly when considering Rod's [Committee member] point about inflexibility and the perception that older workers are inflexible... Perhaps a long-term unemployed female presenting herself to an employer is less of a threat to that employer and less of a potential problem. (Public Hearing, 16 September Adelaide, pp. 367-368) 
In the case of the hidden unemployed female identity, women's domestic and caring responsibilities were also used to construct versions of relative feminine privilege. This was seen as bestowing a gendered advantage in accounting for periods of unemployment in the construction of work history. Women could use family responsibilities as an excuse for periods out of the workforce whereas men could not. This is illustrated in the following exchange between a committee member and an older unemployed man. Both the personal nature of the interaction and the importance of personal experience in work and unemployment are highlighted through the informational prominence given to pronouns 'I', 'you', 'they': essentially the committee member is trying to assist the older male worker by giving advice based on her experience and it is in this context that she also offers family ('childbirth or something') as an explanation for women’s greater 'advantage'.

Ms GAMBARO [Committee member] -You have described your resume as being very extensive. I have worked in the personnel industry as well and I have had people tell me that when they have omitted the fact that they were a manager of a company and left out a few key threatening positions.

Witness - They got the job.

Ms GAMBARO - They were able to obtain work. Have you ever tried that?

Witness - Yes, I have tried that as well... targeted CVs. One of the problems with targeted CVs is that it means there is a big gap, 10 years in this guy's life, that is not explained.

Ms GAMBARO [Committee member] - Women can attribute that to childbirth or something, yes. So you have done that and people say to you. "Well, why is there a gap here?” I can understand that. (Public hearing Wednesday 15 September 1999, Perth, p. 275).

Older women were thus constructed as enjoying greater freedom than older men in constructing their work biography: not only were they not locked into a career (Public Hearing, 9 Sept Ringwood, 1999, p. 239) and therefore more easily employable in low skill, low paid, casual jobs; they could also attribute unemployment to family responsibilities in ways that older men could not. 
In both constructions of older female advantage, the basis for that advantage was greater fluidity in work-based identity. In the case of the flexible female, less attachment to an occupation or career and greater work discontinuity, together with gendered norms about suitable employment, were used to argue that older women were comparatively advantaged in gaining employment, relative to older men. In the case of the hidden unemployed, women's greater responsibilities for family and childcare were used to argue they enjoyed greater freedom to move in and out of work in ways that advantaged them in accounting for periods of unemployment. Both cases illustrate how widely acknowledged characteristics of women's disadvantage in the labour market could be reframed as signifiers of women's relative advantage. Our analysis shows that the female older worker was rendered invisible because she was constructed as privileged, compared to older male workers, and thus not in need of government assistance.

\section{Policy Implications}

The findings illustrate how the relational nature of identity construction can easily become competitive in policy contexts where "most disadvantaged" status confers access to greater public recognition and government benefits. The degree of disadvantage associated with a particular category of identity thus became an advantage in terms of being constructed as needing government and other support. Constructions of older women's comparative advantage, relative to older men, were founded on the notion of their greater flexibility and its positive connotations. In this context, traditional sources of women's disadvantage in the labour market (lower paid, tenuous employment, discontinuous work histories, responsibility for childcare) were reframed as signifiers of their relative privilege, compared to older men. The discursive struggle to achieve recognition as the most disadvantaged group in the labour market relied on positioning other groups in opposition to, and competition with, older workers and this resulted in a dominant construction of older workers as older white men. 
Such a construction does not acknowledge the intersection of age with other differentiated social identities (such as ethnicity and gender) and shows how the competitive nature of identity politics in public policy limits the ability to admit complexity and fluidity in the construction of identity categories. Competing for scarce public resources and public recognition led to a reduction of complexity in this case because a clearly defined and homogenous identity made a better basis for arguing their comparative disadvantage.

These discursive maneuvers, which served to construct feminine versions of older workers as privileged, also reproduced existing definitions relating to the category of “unemployment”. In the Australian context, if an individual works in paid employment at all in the preceding week, even for as little as one hour, they are formally classified as employed for the purposes of government data collection and access to publicly funded benefits and services (ABS 2006). Because the flexible female was constructed as able to obtain paid employment, albeit in low skill, low paid, tenuous employment, she was by this definition counted as employed. The terms of reference of the inquiry were based on this definition and, as such, it was concerned with investigating the barriers older people faced in gaining employment or starting a small business, after a period of unemployment, from which the flexible female identity was excluded. The discursive manoeuvers in the Inquiry's texts served to reproduce this assumption - that by being flexible, this female construction did not warrant additional support or any change in existing definitions. The hidden unemployed version of older worker identity also remained hidden because of the definition of identity categories. Because there was no government definition of hidden unemployment, the category was not recognized for the purposes of government data collection; and, because there was no data collection, there was little aggregated statistical evidence on which to draw in making a case for support. Therefore, at the end of the inquiry, the hidden unemployed remained largely unknown and unknowable (Votes and Proceedings, House of 
Representatives 2000) in ways that illustrate the circular dynamic of identity construction, recognition and policy formulation.

\section{The Older Worker as Lacking Self Esteem}

A second common pattern we noticed in relation to versions of the older male worker were that it was regularly associated with a range of psychological terms, most notably selfesteem and specifically low self esteem. Here we see the overlap between our first and second findings as the comparative disadvantage of older male workers was also promoted through the use of psychological and psychotherapeutic discourse, which featured in the inquiry. For example, the foreword to the final report written by the Chair of the committee opened with a depiction of unemployment in terms of the loss of meaning and identity:

Australia is a country in which we define ourselves through our work. Within minutes of meeting one another the question is asked: "What sort of work do you do?” Work puts us in a social context, defines the framework of our lives and gives each of us a sense of belonging and meaningful purpose. (Age Counts 2000: ix)

Older male workers were thus constructed as more disadvantaged, compared to older women as well as younger unemployed people, because the loss of paid work was represented as having a greater impact on their sense of self than was the case with these two other groups (e.g. Public hearing, Thursday 26 September 1999, p. 426 quoted earlier). This served to position older male workers as more worthy of public sympathy and government attention and support than younger unemployed people or older women.

\section{Comparative (Dis)advantage}

Hewitt (1998) has argued that self esteem can be used to mean (a) unqualified self approval, where individuals feel good about themselves, regardless of what they do or have achieved; or (b) it can take the form of self respect, where self-esteem is attained by accomplishing something of social value. We analyzed instances where self-esteem was mentioned in the inquiry texts and found that both meanings were present. However, there were clear patterns in the way in which these different meanings of self-esteem were related 
to the older and younger unemployed. Specifically, older workers were constructed as having attained self-esteem by earning it through years of accomplishment and achievement in employment and social life; while younger workers were constructed as having unearned selfesteem, as illustrated in the following quotation:

[T]hose recently emerging from the trauma of ejection/rejection by their previous employer, for whom they will usually have worked for a considerable period, often do not present the same kinds of brash and confident front as younger workers (Submission 78).

There was thus a contrast between a conception of the self as institutionally anchored i.e., located in institutional frameworks where self-identity and self-esteem stemmed from living up to social expectations and institutional roles, and an impulsive self, where identity and selfesteem emanated from individual impulses, following free self-expression. The former was a positive construction, the latter a negative one.

The positive construction of self esteem translated into a comparative disadvantage for the older worker compared to his younger counterpart since it meant that unemployment was far more damaging to the older worker’s self esteem. In the following quotation, the older male worker is constructed as an object of sympathy by a consistent focus on their emotional and psychological state through the repetition of mental processes ('embarassed', 'resent', 'detest' 'feel') which forms part of an associated pattern of lexical cohesion ('feel unworthy', 'feel', 'lost self-respect', 'lost the respect'):

Many of ... the over 45's are now facing unemployment. They find it difficult to accept being placed on the scrap heap and are embarrassed to queue up for Dole [unemployment] payments. They resent being questioned by someone half their age and they detest being patronized. They feel unworthy; they have lost their own selfrespect and feel they have lost the respect of their families. Many would give anything just to be able to earn a full week's wage and go back to what they came from. (Submission 101)

Unemployment erased or reversed previous accomplishments and achievements that provided the basis of self-esteem. In constructions of older unemployment, self-esteem and its companion terms ('self-respect') were assumed to be important and desirable social goods 
with which elected politicians should be concerned. Some submissions relied on more intimate constructions of reader-writer relations to invite committee members to imaginatively identify with older unemployed ('it could happen to you') by featuring mental processes ('reflect', 'envisage') as well as personal pronouns ('your working lives', 'your reaction’ etc):

It is the concept of meaningful work that is central to the dilemma of the skilled, mature-age unemployed. Place yourselves in my position; reflect upon your working lives prior to your political careers, and envisage what your reaction would be to $400+$ people telling you your services were not wanted, and proffering no valid reason why that should be so. I suggest that, as with me, the effect on your self-esteem, your selfreliance, sometimes your self-respect, would be devastating. The notion that the expenditure and devotion of significant effort, energy, and achievement over the best years of your adult life can, almost overnight, be rendered an exercise in futility, becomes a very tangle psychological hurdle. (Submission 153)

Re-entry into paid work was the only way in which earned self-esteem could be rebuilt and, thus, only paid work could offer a lasting solution to the damaged self-esteem of older workers.

Many clients who have had 10 to 20 years of senior responsibility have stated that all they want is a job and income to help restore their own self-esteem (Submission 114).

This particular construction - and privileging - of self-esteem resulted in a comparative disadvantage for older workers: given that older workers had earned their self-esteem rather than simply claiming it, as younger workers did, paid employment was the only way to retrieve it, especially in the light of the broader social bias against older people in favour of the young. Moreover, the loss of self esteem was more significant for the older worker than for younger people whose self-confidence of unqualified self-approval would allow them to easily reclaim it.

In relation to the female older worker, this particular meaning of self-esteem also reinforced the dominance of masculine versions of older worker identity. The male older worker was constructed as the head of a traditional family, as a result of which the negative effects of his unemployment flow on to the rest of the family. Importantly he is not 
constructed as an actor who causes these negative changes but, rather, he experiences them: he is 'done to', he 'suffers' and he 'feels'. Similarly his marriage 'breaks down', he did not 'break it'. The use of mechanical imagery ('scrap heap', ‘falls apart', 'breakdown') helps to convey a sense that psychological change (his damaged self-esteem) has material consequences.

If the head of the family, no longer in gainful employment, suffers from low selfesteem as a consequence and feels that he is left on the scrap heap ... then the whole family suffers and falls apart. His children refuse to listen to him, in fact his whole character changes, as it did in my case and this often leads marriages to break down. (Submission 162)

This scenario constructs older worker identity in a clearly gendered form, stressing the greater importance of work-based identity to men and hence the greater impact unemployment had on male self-esteem. This gendered construction was repeated elsewhere. In the following excerpt a comparison is established at the outset between the position of older male and older female workers in order to argue that older men deserve more government attention and assistance and public sympathy. The older male unemployed are the consistent focus, the repeated theme of sentences and the writer uses extreme language 'life threatening', 'last', 'crucial' without any modifying or qualifying terms. Relational processes dominate giving the impression that the writer is describing what he sees as 'factual' attributes of older men's current circumstances and he relies on contemporary, even 'new age', emotional and psychological discourse to emphasize its importance ('mind, body and spirit').

Mature male unemployment is a more life threatening condition than mature female unemployment...Mature male unemployment exposes the marginal emotional dignity which is afforded males in contemporary society. Employment is the last raison d'etre for the vast majority of men. It is the crucial focus for male energy, mateship and selfesteem. Male unemployment at any age is bad. At a mature age premature male unemployment is a sentence of mind, body and spirit. (Submission 141)

Here the meaning of self-esteem relies on broad cultural understandings of two key gendered institutions - employment and the family - and the loss of self-esteem was used in nostalgic constructions of traditional gender roles. Older male workers were constructed as more 
worthy of public sympathy and government attention because the loss of work for them had different and more significant meanings than it did for older women. Moreover, negative change in male self-esteem was depicted as not only detrimental to the individual (male) but also to the family of which he was head. This, in turn, was represented as increasing the burden on the rest of society, through increased social problems, increased health care costs, and contributing to long-term unemployment.

Sustained high levels of mature male unemployment creates tensions in society. These tensions are often manifested in self abuse, and an increase in violence and crime towards others. (Submission 141)

Thus the older (male) worker needed more support in finding employment than both his female and younger counterparts - both for his own sake and that of society.

\section{Policy Implications}

Constructing the problem of older unemployment in ways that privileged its psychological affects gave rise to policy recommendations that were also framed in psychological terms and which would repair self esteem, as indicated in the following submission..

Compulsory SELF ESTEEM component should be included in any training course undertaken by mature age people (Submission 113.1)

The older unemployed were therefore encouraged to participate in raising their self-esteem as part of an overall project of self-improvement, self-help and self-reliance. For example, training and volunteer work were repeatedly mentioned as mechanisms for the restoration of self esteem:

Voluntary work was seen to invigorate social contact again and alleviate boredom while benefiting community organizations. It improved self-esteem and provided stimulation. It was also useful in the transition period after losing a job. (Submission 109)

The dominant remedy that was promoted was individual action and initiative even though older workers were warned that, in the longer term, such a restoration in self-esteem would be 
temporary and individuals would regress unless they were able to secure their identity by regaining meaningful employment.

The BHP experience has indicated that retraining can give people added confidence and increase their skill levels although this will be of no advantage if there are no real job opportunities to use those acquired skills. (Submission 143)

Such solutions lead to the individualization of social inequality, and the promotion of individual remedies, which were conservative insofar as they were targeted at the individual rather than at the wider system or broader social and political structures.

The construction of older male unemployment as a self-esteem based problem also functioned to positively reinforce the role of many of the employment and welfare agencies who had appeared before or made submissions to the inquiry. Because of low self-esteem, the older unemployed were viewed as ill-equipped to engage in job search activities and selfpromotion or self-marketing. So, self-help initiatives needed to be mediated by experts.

Older persons also in many cases lack self-esteem and do not know how to take the initiatives and promote themselves to find employment. They need job finding skills support (Submission 122).

Their depiction as being unable to engage in this project of the self precisely because they had damaged self-esteem, as well as being caught in a downward spiral of compounding social and economic disadvantage created a need for other actors, such as employment agencies and welfare groups to speak on their behalf and to intervene through counseling or training, also constructed in therapeutic terms. This results in a paradox that reinforced current institutional arrangements: constructing the problem of older (male) unemployment in terms of damaged self-esteem led to self-esteem based solutions that inferred that low self-esteem was the responsibility of the individual to remedy. However, precisely because older (male) workers had low self-esteem, they were unable to help themselves and needed public assistance to remedy this psychological damage, shoring up the role of employment and welfare agencies within the current labour market system and minimizing the pressure for broader change. 


\section{Discussion and Conclusions}

We argue that discourse analysis is useful because it allows us to focus on the construction of identity categories themselves and explore their implications. This is particularly relevant for the study of age identity categories because of their fluid and shifting boundaries (e.g., the different points at which the worker becomes “old”), as well as the inherent complexity of establishing the older worker as the "Other" when most of us expect, and even hope - given that the alternative is not particularly attractive - to become old. In contrast, boundaries around ethnicity and gender are for the most part clearer (or at least constructed as visible), and those who traverse them are the exception rather than the rule.

Our findings illustrate some of the ways in which certain constructions of the older worker are privileged as well as the paradoxes associated with struggles for identity recognition in general, and age identity in particular, as they are played out in public policy contexts. They highlight the complexity of age identity construction: discourses of age and age identities cannot be researched in isolation because they inevitably occur in conjunction with, and interact with, other social identities (e.g. gender) and other discourses, which are used to construct identity categories. They also show that the competitive dynamic about comparative disadvantage underpinning the relational nature of identity construction in this context led to a reduction of complexity, with masculine versions of older workers dominating the final texts and policy recommendations.

Discursive complexity did not only stem from the relational nature of identity construction but also from the broader discourses used to construct older workers as an object of public policy. In this study, we showed how the psychological aspects of older unemployment were foregrounded and specifically, how older (male) workers were constructed as having damaged self-esteem. Such a construction drew on psychotherapeutic discourse to position older (male) workers as culturally sympathetic figures worthy of 
government and public attention and resources. However, instead of underscoring the importance of change to current systems and structures, this discourse contributed to maintaining the status quo. Our analysis was thus able to show not only the competitive dynamic underpinning struggles for identity recognition and their effects but also its inherent circularity - once a discourse is used to construct an object of public policy and takes hold, it influences the type of policy recommendations that "make sense".

The reason for this outcome partly relates to the nature of the discourse itself. Psychotherapeutic and psychological discourse centre on the individual. When explanations of social disadvantage and discrimination arising from group membership (such as age) rely on such discourse (as in the language of self-esteem), the result is individualizing solutions. This is a contradiction that has broader implications for discourses of difference research. The reason that the older worker category has attracted attention is because it is recognized as a social identity or group that is experiencing difficulties because of group-related characteristics, such as age discrimination. However the way the social category is discursively constructed in this policy context reduces problems experienced as a result of group category membership to individually-based characteristics, particularly relying on common sense psychological terms such as self-esteem (cf. Beck 1992). Such discursive construction undermines the possibility for a collective response to age discrimination because it reduces it to an individual-level problem (cf. Gullette 1997) that is the responsibility of the older individual to remedy.

The reduction in complexity may also be a consequence of the public policy context of this study. While such contexts allow researchers to explore both the processes of identity category construction and their affects, the material implications of such categories mean they are relatively intransigent. From a public policy perspective, just as one cannot be allocated to both the employed and unemployed categories, one cannot be recognized as a sole parent and 
as one of the unemployed - these identity categories were mutually exclusive. The hidden unemployed remained hidden because her sole parent status precluded her being counted as a worker, therefore she could not be unemployed. In the inquiry, identity categories in public policy were thus relatively stable and resistant to attempts to change them, firstly because loosening or changing the category boundaries may have, by definition, resulted in more unemployment and secondly, because identity categories have material implications. This illustrates a gap between academic interest in identity construction and material constraints. The idea of identity as multiple, ambiguous, fluid and intersecting has become widely accepted within academic literature (e.g. Hall 1996, Wetherell 2001), yet in the case of the hidden unemployed, attempts to claim multiple membership of identity categories were unsuccessful. Identity categories are illuminating for discourse scholars because they yield insights into how categories are constructed and maintained, and their material implications. However it is precisely because they have material implications that they are hard to change and mutually exclusive.

\section{References}

ABS (2006) Australian Bureau of Statistics, Labour Statistics: Concepts, Sources and Methods, 2006, (6102.0.55.001) published online at http://www.abs.gov.au/AUSSTATS/abs@.nsf/Latestproducts [accessed 19/07/2006]

Ainsworth, S. (2002) 'The feminine advantage: a discursive analysis of the invisibility of older women workers', Gender Work and Organization, 9(5): 579-601.

Ainsworth, S. and Hardy, C. (2004) 'Critical discourse analysis and identity: why bother’, 
Critical Discourse Studies, 1(2): 225-259.

Beck, U. (1992) Risk Society: Towards a New Modernity. London, Newbury Park, New Delhi: Sage.

Cameron, D. (1997) ‘Performing gender identity: young men’s talk and the construction of heterosexual masculinity' in Language and Masculinity. S. Johnson and U H. Meinhof (eds.), Oxford: Blackwell, pp. 47-64.

Coupland, N., Coupland, J. and Giles, H. (1991) Language, Society and the Elderly: Discourse, Identity and Ageing. Oxford UK and Cambridge USA: Blackwell.

Coupland N. and Nussbaum, J.F. (eds.) (1993) Discourse and Lifespan Identity. Newbury Park, CA: Sage.

Duncan, C. (2001) 'Ageism, early exit, and the rationality of age-based discrimination', in Ageism in Work and Employment, Ian Glover and Mohamed Branine (eds.), Aldershot: Ashgate, pp. 25-46.

Edley, N. and Wetherell, M. (1997) 'Jockeying for position: the construction of masculine identities’. Discourse \& Society 8(2): 203-217.

Encel, S. (2003) Age Can Work: The Case for Older Australians Staying in the Workforce. A Report to the Australian Council for Trade Unions and the Business Council of Australia, April. 
Fairclough, N. (1995) Critical Discourse Analysis: the Critical Study of Language. London: Addison Wesley Longman.

Fowler, R. (1991) Language in the New: Discourse and Ideology in the Press. London and New York: Routledge.

Fowler, R. (1996) 'On critical linguistics’ in Texts and Practices: Readings in Critical Discourse Analysis. C.R. Caldas-Coulthard and M. Coulthard (eds.), London: Routledge, pp. 3-14.

Garnsey, E. and Rees, B. (1996) 'Discourse and enactment: gender inequality in text and context'. Human Relations 49(8): 1041-1063.

Gill, R. (1993a) ‘Justifying injustice: broadcasters’ accounts of inequality in radio’ in Discourse Analytic Research: Repertoires and Readings of Texts in Action. E. Burman and I. Parker (eds.), 75-93. London: Routledge.

Gill, R. (1993b) ‘Ideology, gender and popular radio: a discourse analytic approach’. Innovation 6: 323-39.

Glover, I. and Branine, M. (2001) 'Introduction: the challenge of longer and healthier lives', in Ageism in Work and Employment, Ian Glover and Mohamed Branine (eds.), Aldershot: Ashgate, pp. 3-21. 
Gullette, M. M. (1997) Declining to Decline: Cultural Combat and the Politics of the Midlife. Charlottesville and London: University Press of Virginia.

Hacking, I. (2000) The Social Construction of What? Cambridge MA and London: Harvard University Press.

Hall, S. (1996) 'Introduction: who needs identity?’ in Questions of Cultural Identity. S. Hall and P. du Gay (eds.), London, Thousand Oaks CA, New Delhi: Sage, pp. 1-17.

Halliday, M.A.K. and Matthiessen, C.M.I.M. (2004) An Introduction to Functional Grammar, $3^{\text {rd }}$ edition. London: Arnold.

Hewitt, J. P. (1998) The Myth of Self Esteem: Finding Happiness and Solving in America. New York: St. Martin’s Press.

Kleiner, B. (1998) 'The modern racist ideology and its reproduction in "pseudo-argument”'. Discourse \& Society 9(2): 187-215.

Laclau, E. (1990) New Reflections on the Revolution of our Time. London: Verso.

Loretto, W. and White, P. (2006) 'Employers' attitudes, practices and policies towards older workers’, Human Resource Management Journal, 16(3): 313-330.

McGoldrick, A. E. and Arrowsmith, J. (2001) 'Discrimination by age: the organizational response', in Ageism in Work and Employment, Ian Glover and Mohamed Branine (eds.), 
Aldershot: Ashgate, pp. 75-96.

McMahan, S. and Phillips, K. (2000) 'Aging and employment: characteristics of those working and retired in California’. Journal of Education for Business 76(1):11-18.

OECD (Organisation for Economic Co-operation and Development), (2005) Ageing and Employment Policies: Australia, OECD Publishing.

Paltridge, B. (2000) Making Sense of Discourse Analysis, Gold Coast, Qld: Antipodean Educational Enterprises.

Pearson, B. (2003) ‘Japan battles an ageing nation’. The Weekend Australian Financial Review, October 25-26: 10.

Phillips, N. and Hardy, C. (1997) 'Managing multiple identities: discourse, legitimacy and resources in the UK refugee system’. Organization 4(2): 159-185.

Pomerantz, A. and Fehr, B.J. (1997) 'Conversation analysis: an approach to the study of social action as sense making practices' in Discourse as Social Interaction Discourse Studies: A Multidisciplinary Introduction, Volume 2. T. A. van Dijk (ed.), London: Sage, pp. 64-91.

Redman, T. and Snape, E. (2002) 'Ageism in teaching: stereotypical beliefs and discriminatory attitudes towards the over-50s', Work, Employment and Society, 16(2): 355371. 
Stephenson, P. H., Wolfe, N. K. Coughlan, R., and Koehn, S. D. (1999) ‘A methodological discourse on gender, independence and frailty: applied dimensions of identity construction in old age'. Journal of Aging Studies 13(4): 391-401.

Tannen, D. (1994) Gender and Discourse. New York and Oxford: Oxford University Press.

Tannock, S. (1999) 'Working with insults: discourse and difference in an inner-city youth organization’. Discourse \& Society 10(3): 317-350.

Taylor, P. and Walker, A. (1998) 'Employers and older workers: attitudes and employment practices', Ageing and Society, 18(6): 641-658.

Tretheway, A. (2001) 'Reproducing and resisting the master narrative of decline' Management Communication Quarterly 15(2): 183-226.

Van Dijk, T.A. (1984) Prejudice in Discourse: An Analysis of Ethnic Prejudice in Cognition and Conversation. Amsterdam and Philadelphia: John Benjamins Publishing.

Van Dijk, T.A. 1996 'Discourse, power and access' in Texts and Practices: Readings in Critical Discourse Analysis. C.R. Caldas-Coulthard and M. Coulthard (eds.), London: Routledge, pp. 84-106.

Van Dijk, T. A. (1997) 'Political discourse and racism: describing others in Western parliaments' in The Language and Politics of Exclusion, S.H. Riggins (ed.), Thousand Oaks CA: Sage, pp. 31-64. 
Van Dijk, T.A. (2001) 'Multidisciplinary CDA: a plea for diversity', in Methods of Critical Discourse Analysis, Ruth Wodak and Michael Meyer (eds), Sage: London. pp. 95-120.

Wetherell, M. (2001) 'Minds, selves and sense-making' in Discourse Theory and Practice: A Reader. M. Wetherell, S. Taylor and S.J. Yates, (eds.), London: Sage and Open University, pp. 186-197.

Wetherell, M. and Potter, J. (1992) Mapping the Language of Racism: Discourse and the Legitimation of Exploitation. London: Harvester Wheatsheaf.

Williams, A., Coupland, J. Folwell, A. and Sparks, L. (1997) 'Talking about Generation X: defining them as they define themselves'. Journal of Language and Social Psychology 16(3): 251-277.

Wodak, R. (1996) ‘The genesis of racist discourse in Austria since 1989’ in Texts and Practices: Readings in Critical Discourse Analysis. C.R. Caldas-Coulthard and M. Coulthard (eds.), London: Routledge, pp. 107-128.

Wodak, R. (1997) 'Das Ausland and anti-semitic discourse: the discursive construction of the other' in The Language and Politics of Exclusion. S.H. Riggins (ed.), Thousand Oaks, CA:Sage, pp. 65-87.

Ylanne-McEwen, V. (2000) 'Golden times for golden-agers: selling holidays as lifestyle for the over 50s'. Journal of Communication 50(3): 83-99. 


\section{University Library}

\section{- M M I N E R VA A gateway to Melbourne's research publications}

Minerva Access is the Institutional Repository of The University of Melbourne

Author/s:

Ainsworth, S; Hardy, C

Title:

The construction of the older worker: privilege, paradox and policy

Date:

2007-08-01

Citation:

Ainsworth, S. \& Hardy, C. (2007). The construction of the older worker: privilege, paradox and policy. DISCOURSE \& COMMUNICATION, 1 (3), pp.267-285. https:// doi.org/10.1177/1750481307079205.

Persistent Link:

http://hdl.handle.net/11343/116073 